\title{
Signaling and metabolic properties of fast and slow smooth muscle types from mice
}

\author{
Lena Boberg ${ }^{1} \cdot$ Ferenc L. M. Szekeres ${ }^{2} \cdot$ Anders Arner $^{1}$
}

Received: 25 October 2017 / Revised: 8 December 2017 / Accepted: 13 December 2017 / Published online: 29 January 2018

(C) The Author(s) 2018. This article is an open access publication

\begin{abstract}
This study aims to improve the classification of smooth muscle types to better understand their normal and pathological functional phenotypes. Four different smooth muscle tissues (aorta, muscular arteries, intestine, urinary bladder) with a 5-fold difference in maximal shortening velocity were obtained from mice and classified according to expression of the inserted myosin heavy chain (SMHC-B). Western blotting and quantitative PCR analyses were used to determine 15 metabolic and 8 cell signaling key components in each tissue. The slow muscle type (aorta) with a 12 times lower SMHC-B had 6-fold lower expression of the phosphatase subunit MYPT1, a 7-fold higher expression of Rhokinase 1, and a 3-fold higher expression of the PKC target CPI17, compared to the faster (urinary bladder) smooth muscle. The slow muscle had higher expression of components involved in glucose uptake and glycolysis (type 1 glucose transporter, 3 times; hexokinase, 13 times) and in gluconeogenesis (phosphoenolpyruvate carboxykinase, 43 times), but lower expression of the metabolic sensing AMPactivated kinase, alpha 2 isoform (5 times). The slow type also had higher expression of enzymes involved in lipid metabolism (hormone-sensitive lipase, 10 times; lipoprotein lipase, 13 times; fatty acid synthase, 6 times; type 2 acetyl-coenzyme A carboxylase, 8 times). We present a refined division of smooth muscle into muscle types based on the analysis of contractile, metabolic, and signaling components. Slow compared to fast smooth muscle has a lower expression of the deactivating phosphatase and upregulated $\mathrm{Ca}^{2+}$ sensitizing pathways and is more adapted for sustained glucose and lipid metabolism.
\end{abstract}

Keywords Contractile kinetics $\cdot$ Energy metabolism $\cdot$ Myosin isoforms $\cdot$ Phasic $\cdot$ Shortening velocity $\cdot$ Tonic

\section{Introduction}

Smooth muscle performs a wide range of important physiological tasks, including the rapid contractions of the urinary bladder to expel urine and the sustained tension maintenance in the wall of arteries to maintain blood pressure. Although they all share the common smooth structural appearance, the smooth muscle types are uniquely adapted to their requirements and exhibit a broad range of structural, mechanical, regulatory, and metabolic properties. Still, it has not been

L.B. and F.S. contributed equally to this work.

Anders Arner

Anders.Arner@ki.se

1 Department of Physiology and Pharmacology, Karolinska Institutet, v Eulers v 8, 17177 Stockholm, SE, Sweden

2 School of Health and Education, University of Skövde, Skövde, Sweden possible to clearly identify specific smooth muscle types. In early work by Emil Bozler [8], smooth muscle was divided in two main groups, "single unit" (unitary/visceral) and "multiunit" types, based on their regulation via motor nerves and cellular electrical coupling. Although this division is present in most textbooks on muscle physiology, it does not fully describe the diversity of the tissue. More recently, the group of Somlyo and Somlyo divided smooth muscles in "phasic" and "tonic" types, based on the contractile responses to activation $[20,49,52]$. The phasic muscles, e.g., in the mesenteric vein and ileum, exhibit a rapid, transient, contractile response, whereas the tonic muscles, e.g., in large arteries, have a slower force development, but a sustained contraction. It was subsequently shown that these two groups of muscle have differences in cellular signaling, contractile kinetics, and nucleotide affinity, e.g., [17, 18, 21, 22, 28]. In general, comparative data show a variation in several other properties of tonic and phasic smooth muscles, e.g., [16].

It seems logical to divide muscles according to the properties of contractile system, and in the striated muscle the 
division into muscle types can be made based on the expression of the myosin heavy chain genes, which correlates with the contractile kinetics [46]. In smooth muscle, myosin is generated from one main smooth muscle heavy chain gene with the addition of non-muscle myosins [53]. Still, smooth muscle exhibits a large span in contractile kinetics from slow arterial muscles to the almost seven times faster visceral types [36]. It has been shown that faster kinetics of actin-myosin interaction in smooth muscle correlates with a higher relative expression of an inserted myosin heavy chain isoform [27] and with a higher relative expression of a smooth muscle variant of the essential 17-kDa myosin light chain (LC17a, [36, 51]). The exact role of these smooth muscle myosin isoforms in determining the cross-bridge kinetics is still not fully clear, both potential mechanisms have been challenged [1,27], and it is possible that these variants are expressed in a coordinated way. Additional considerations are, e.g., the role of the nonmuscle myosin, which can be expressed in significant amounts in smooth muscle and support a slow contraction $[32,38,43]$ and other regulatory proteins, e.g., calponin [23]. Irrespective of potential mechanisms, a strong correlation is observed between the maximal shortening velocity, reflecting cross-bridge turnover, and the expression of the myosin heavy chain insert and the essential light chain isoforms [3], both parameters being potential markers for the smooth muscle contractile phenotype.

The smooth muscle contractile system is, in comparison to that of striated muscles, more complex with regard to its regulation since the myosin-based phosphorylation process is subject to an extensive signaling network affecting the $\mathrm{Ca}^{2+}$ sensitivity of the contraction, mainly via the RhoA-Rhokinase and protein kinase $\mathrm{C}$ (PKC) pathways, e.g., [50]. Also, regarding this aspect of smooth muscle contraction, tissue variability has been reported in several studies, e.g., regarding phosphatase expression, and PKC and RhoA expression [18, 40, 54].

The contractile and regulatory processes in muscle are tightly linked to cellular energy turnover. The metabolism of intact smooth muscle tissue has been studied, and pioneering work demonstrated a low energy turnover and high lactate production under aerobic conditions, cf. Paul [41, 42]. A variation in metabolic tension cost between smooth muscles is seen, cf. [41, 42], but a more extensive link between smooth muscle type and metabolism is not available.

Smooth muscle thus converts metabolic energy to mechanical work regulated by an extensive and complex cellular signaling. It is possible that an improved division into smooth muscle types can be achieved by considering the three main components of the smooth muscle contraction: contractile properties, cellular signaling, and energy metabolism. Although the smooth muscle is multicellular and complex, such a consideration at the tissue level might be an important first step to understand how smooth muscle is adapted to its physiological environment and altered in response to pathological events and disease. The main objective of this study was therefore to develop a characterization of signaling and metabolism in relation to contractile kinetics by comparing different types of smooth muscle tissues from one species. We report on four smooth muscle tissues from mouse, with a large span in contractile kinetics, where we measured 15 metabolic and 8 cell signaling components, and summarize the main characteristics of fast and slow smooth muscle phenotypes.

\section{Methods}

\section{Animals and tissues}

The study was performed on adult female and male C57/B16 mice. The animals were euthanized by cervical dislocation and the different smooth muscle tissues were dissected. We included urinary bladder (freed from urothelium), muscular arteries (superior mesenteric artery and femoral artery), aorta, and the outer longitudinal layer of the small intestine. The tissue samples (about $1-2 \mathrm{mg}$ ) were rapidly frozen in liquid $\mathrm{N}_{2}$ and kept at $-80^{\circ} \mathrm{C}$ until analysis with gel electrophoresis or real-time PCR. All husbandry and experiments were approved by the local animal ethics committee and conformed to the European Convention for the Protection of Vertebrate Animals used for Experimental and other Scientific Purposes (Council of Europe No. 123, Strasbourg 1985).

\section{PCR analysis of mRNA expression}

The mRNA was extracted (RNeasy Kit; Qiagen) from four different types of smooth muscle tissue (urinary bladder, intestine, aorta, femoral artery). Quality and concentrations were assayed using a NanoDrop spectrophotometer at 260/280 nm (>1.9) and 260/230 nm (>2.0). High Capacity Reverse Transcription Kit (Applied Biosystems) was used to generate cDNA. The cDNA of the metabolic enzymes was analyzed (in duplicates) by quantitative real-time PCR (RT-qPCR) using 96-well plates on an Applied Biosystems real-time PCR using Fast SYBR Green MasterMix (Applied Biosystems). All samples were diluted to the same concentration before running the qPCR. Primers for each gene are listed in Table 1. We confirmed using agarose gel electrophoresis that all primers resulted in one PCR product. The amount was quantified using the relative standard curve method with the pooled samples from all tissues as a standard and normalized to HPRT (hypoxanthine-guanine phosphoribosyltransferase).

Standard PCR (40 cycles), agarose gel electrophoresis (4\% gels), and analysis using Quantity One software (Bio-Rad) were used for the determination of the relative concentration of inserted smooth muscle myosin heavy chain (SMHC-B) using the following primers [33]: forward, ATGTACAA 
Table 1 Primers used for RT-qPCR analysis of the mouse samples

\begin{tabular}{|c|c|c|}
\hline Protein, NCBI mRNA accession number & Forward & Reverse \\
\hline $\begin{array}{l}\text { ACC2 } \\
\text { NM_133904 }\end{array}$ & GAATCTCACGCGCCTACTATC & CCTGCACAGAGATTTCACCGT \\
\hline $\begin{array}{l}\text { AMPK } \alpha 1 \\
\text { NM_001013367 }\end{array}$ & GTCAAAGCCGACCCAATGATA & CGTACACGCAAATAATAGGGGTT \\
\hline $\begin{array}{l}\text { AMPK } \alpha 2 \\
\text { NM_023991 }\end{array}$ & AAGATCGGACACTACGTCCTG & TGCCACTTTATGGCCTGTCAA \\
\hline $\begin{array}{l}\text { FAS } \\
\text { NM_007988 }\end{array}$ & GGAGGTGGTGATAGCCGGTAT & CTGGGCTCTATGGATTACCCA \\
\hline $\begin{array}{l}\text { G6PDH } \\
\text { NM_173371 }\end{array}$ & ATGAAGCACACAGGCATTTGG & GGACTGTTTCAGCTATACCTGGA \\
\hline $\begin{array}{l}\text { GLŪT1 } \\
\text { NM_011400 }\end{array}$ & TCAAACATGGAACCACCGCTA & TTCCTTCTCTGTCGGCCTCTT \\
\hline $\begin{array}{l}\text { GLŪT4 } \\
\text { NM_009204 }\end{array}$ & TCCCTTCAGTTTGGCTATAACATTG & TGAACAGAGCTACAATGCAACGT \\
\hline $\begin{array}{l}\text { HEX̄OK2 } \\
\text { NM_013820 }\end{array}$ & GTGTGCTCCGAGTAAGGGTG & CCACATTGCCGAATGCCTG \\
\hline $\begin{array}{l}\text { HPRT } \\
\text { NM_013556 }\end{array}$ & GCAGTACAGCCCCAAAATGG & TTGGATACAGGCCAGACTTTGTT \\
\hline $\begin{array}{l}\text { HSL } \\
\text { NM_001039507 }\end{array}$ & CACCCATAGTCAAGAACCCCTTC & CGGTGACGCTGAAAGTGGTAGA \\
\hline $\begin{array}{l}\text { LDH̄A } \\
\text { NM_001136069 }\end{array}$ & CATTGTCAAGTACAGTCCACAC & TCCCAAAAACCGAGTAATTGGAA \\
\hline $\begin{array}{l}\text { LPL }^{-} \\
\text {NM_008509 }\end{array}$ & AGGGCTCTGCCTGAGTTGTA & ACCAGGCCTTCGAAATTTCT \\
\hline $\begin{array}{l}\text { MCD } \\
\text { NM_019966 }\end{array}$ & CTGTCGCCTATCCCTGGATTC & AGAAATCTCAGCCGTTACCGG \\
\hline $\begin{array}{l}\text { PEPCK } \\
\text { NM_011044 }\end{array}$ & ATCTTTGGTGGCCGTAGACCT & AAATACCTGGCCCACTGGC \\
\hline $\begin{array}{l}\text { Pyruvate kinase } \\
\text { NM_001253883 }\end{array}$ & GGCTGAATTTCTCTCATGGAACC & CTACCGTCCTGTTGCGGTG \\
\hline $\begin{array}{l}\text { TFAM } \\
\text { NM_009360 }\end{array}$ & GGAATGTGGAGCGTGCTAAAA & TATTCCGAAGTGTTTTTCCAGCA \\
\hline
\end{tabular}

All primers except AMPK $\alpha 1$ and $\mathrm{AMPK} \alpha 2$ were obtained from [48]

ACC2 acetyl-coenzyme A carboxylase beta; $A M P K \alpha 1$ AMP-activated, alpha 1 catalytic subunit; AMPK 2 AMP-activated, alpha 2 catalytic subunit; $F A S$ fatty acid synthase; G6PDH hexose-6-phosphate dehydrogenase (glucose 1-dehydrogenase); GLUT1 solute carrier family 2 (facilitated glucose transporter); GLUT4 solute carrier family 2 (facilitated glucose transporter); HEXOK2 hexokinase 2; HPRT hypoxanthine-guanine phosphoribosyltransferase; HSL lipase, hormone sensitive; $L D H A$ lactate dehydrogenase A; $L P L$ lipoprotein lipase; $M C D$ malonyl-CoA decarboxylase; PEPCK phosphoenolpyruvate carboxykinase 1; TFAM transcription factor A, mitochondrial

GGGCAAGAAGAGGC; reverse, GAGGAGTTGTCGTT CTTGAC. The inserted and non-inserted forms gave two distinct bands (330 and $351 \mathrm{bp}$ ), and the relative content of the larger product of the inserted mRNA was evaluated.

\section{Western blot analysis}

The tissue expression of signaling components (in urinary bladder, intestine, aorta, and superior mesenteric artery) was analyzed essentially as described previously [7]. In principle, the samples were pulverized using a glass micromortar, dissolved in homogenizing buffer, $1 \% \mathrm{SDS}, 1 \mathrm{mM} \mathrm{Na}_{3} \mathrm{VO}_{4}, 1 \%$ phenylmethylsulfonyl fluoride (PMSF), centrifuged, and analyzed for protein content using the Bio-Rad Protein assay (Bio-Rad, Richmond, CA, USA). The samples were analyzed by SDS-PAGE using a Bio-Rad MiniGel system (Bio-Rad, Richmond, CA). Equal amounts of protein from each sample were loaded on the polyacrylamide gels. After blotting onto nitrocellulose membranes, the bands were visualized using primary antibodies, the enhanced chemiluminescence kit (ECL, Amersham Bioscience), and analyzed using Quantity One software (Bio-Rad). The respective antibodies and polyacrylamide concentration were RhoA (dilution 1:1000, Santa Cruz, 12\%), ROCK1 (1:500, Santa Cruz, 7\%), ROCK2 (1:500, Santa Cruz, 7\%), MYPT-1 (1:500, Santa Cruz, 7\%), CPI-17 (1:1000, Upstate, $15 \%)$, PKC $\alpha$ ( $1: 500$, Santa Cruz, 12\%), Rho GDI (1:500, Santa Cruz, $15 \%)$, and PP $1 \beta(2.5 \mu \mathrm{g} / \mathrm{mL}$, Calbiochem, $12 \%)$.

\section{Statistics}

All values are given as mean \pm SEM, with the number of samples in parentheses. Statistical comparisons were made using Student's $t$ test or, and when appropriate, analysis of variance and the Holm-Sidak method for multiple comparisons 
( $p<0.05$ was considered significant) using log values for the qPCR and Western blot data. Calculations and curve fitting were performed using SigmaPlot and SigmaStat for Windows (SPSS Science, Chicago, IL).

\section{Results}

\section{Myosin heavy chain isoform expression}

As a basis for our comparisons between smooth muscle tissues, with different contractile kinetics, we determined the relative content of mRNA for the inserted myosin heavy chain (SMHC-B). The results are shown in Table 2. The lowest expression was observed in the slow arterial muscles (aorta and the muscular artery) and the highest in the fast muscle type (urinary bladder). The intestinal ileum muscle had intermediate expression, with about $25 \%$ lower relative content than in the urinary bladder. For the presentation of the signaling and metabolic components below, we plotted the data against the relative expression of the inserted heavy chain isoform (SMHC-B), as a marker for the contractile kinetics, with low and high contents indicating slow and fast muscles, respectively.

\section{Expression of signaling components}

A first step was to examine the expression of selected components in the contractile activation, including the myosin light chain phosphatase and the two main $\mathrm{Ca}^{2+}$-sensitizing pathways (Rho-Rhokinase and PKC). For this purpose, we used Western blotting and antibodies previously used for characterization of cell signaling in mouse urinary bladder [7]. For each signaling protein, the amount was normalized to the expression in the fast smooth muscle tissue (i.e., urinary bladder). The content of the myosin targeting subunit (MYPT1) of the myosin light chain phosphatase increased with increasing relative SMHC-B expression, with an about six times higher amount (measured as the total amount including two isoforms separated in the gel) in the fast ileum and urinary bladder compared to the slow aorta smooth muscle (Fig. 1a and Western blot in Fig. 1e), whereas the catalytic subunit, PPI $\beta$ (Fig. 1b), did not differ between tissues. For the protein kinase $\mathrm{C}$ (PKC) pathway, the PKC $\alpha$ content (Fig. 1c) was similar in the tissues. The CPI17 (Fig. 1d) was highly expressed in the aorta, with the other tissues exhibiting a lower and similar expression. For the Rho-Rhokinase $\mathrm{Ca}^{2+}$-sensitizing pathway, the RhoGDI (Fig. 2a), RhoA (Fig. 2b), and ROCK2 (Fig. 2d) did not correlate with the relative SMHC-B expression, whereas the ROCK1 (Fig. 2c and Western blot in Fig. 1e) showed a correlation with SMHC-B expression, slower muscles having higher content.

\section{Expression of metabolic components}

Our next step was to determine expression of components in the energy metabolism pathways in relation to contractile kinetics. This profiling included a larger number of proteins, previously not analyzed in detail in smooth muscle, and we therefore used a RT-qPCR approach, with primers previously used in the mouse ([48], Table 1). We used the femoral artery as an example of a muscular artery. We selected key proteins in the main pathways of energy metabolism (cf. Table 1): (1) glucose uptake/glycolysis (the glucose transporters GLUT 1 and GLUT 4, hexokinase II, and pyruvate kinase), (2) gluconeogenesis (PEPCK = phosphoenolpyruvate carboxykinase), (3) lactate production ( $\mathrm{LDH}=$ lactate dehydrogenase A), (4) the pentose phosphate pathway (G6PDH = hexose-6-phosphate dehydrogenase), (5) mitochondrial turnover (TFAM = mitochondrial transcription factor A), (6) the metabolic sensor AMP-kinase (AMPK $\alpha 1$ and $\alpha 2=$ AMPactivated, alpha 1 and 2 catalytic subunits), and (7) the lipid hydrolysis and synthesis (HSL = hormone-sensitive lipase, $\mathrm{LPL}=$ lipoprotein lipase, $\mathrm{FAS}=$ fatty acid synthase, $\mathrm{MCD}=$ malonyl-CoA decarboxylase, $\mathrm{ACC} 2=$ acetyl-coenzyme A carboxylase beta). For each enzyme, we examined the mRNA expression in relation to the myosin heavy chain expression (SMHC-B) and identified the tissues with significantly higher or lower expression.

For the glycolysis pathway, both the glucose transporter GLUT4 (Fig. 3b) and the pyruvate kinase (PYRK, Fig. 3c) were expressed, with similar expression and no clear correlation with relative SMHC-B expression. However, the GLUT 1 transporter (Fig. 3a) and the key enzyme for glucose uptake, hexokinase (Fig. 3d), were negatively correlated with relative SMHC-B expression. The PEPCK (Fig. 4a) was highly expressed in the slow muscles and negatively correlated with relative SMHC-B expression. The LDH (Fig. 4b), G6PDH (Fig. 4c), TFAM (Fig. 4d), and the AMP-kinase $\alpha 1$ isoform (Fig. 4e) had similar expression and no clear correlation with relative SMHC-B expression. The AMP-kinase $\alpha 2$ isoform (Fig. 4f) was higher in the faster muscles. No clear correlation with SMHC-B expression was noted in the MCD (Fig. 5a) between tissues. The expression of the two lipolysis enzymes,

Table 2 Relative expression of the inserted smooth muscle myosin heavy chain (SMHC-B) mRNA in different smooth muscle tissues of the mouse $(n=$ 6)

\begin{tabular}{|c|c|c|c|c|}
\hline & Aorta & Mesenteric artery & Intestine & Urinary bladder \\
\hline SMHC-B/total SMHC & $0.072 \pm 0.005$ & $0.111 \pm 0.006$ & $0.590 \pm 0.019$ & $0.905 \pm 0.005$ \\
\hline
\end{tabular}



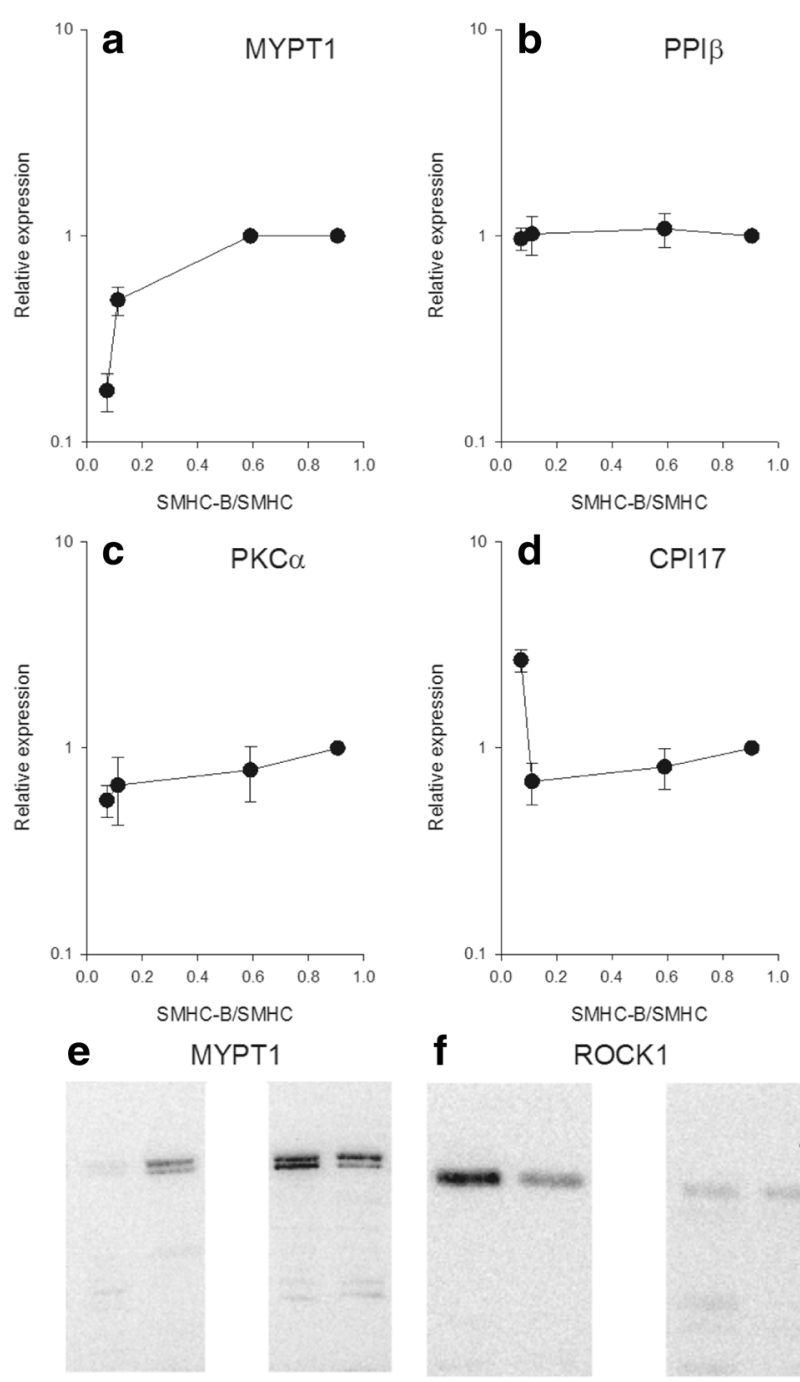

12

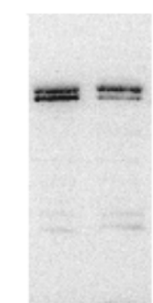

34
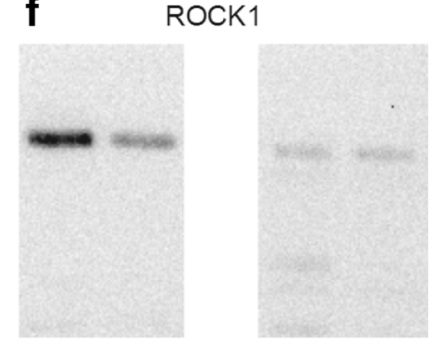

Fig. 1 Expression of signaling components in smooth muscles with different relative expression of SMHC-B. The data show from left to right: aorta, mesenteric artery, ileum, and urinary bladder, $n=4-8$. The Western blot data for the signaling components are given relative to the expression in the urinary bladder. a MYPT1, b PP $1 \beta, \mathbf{c ~ P K C ~} \alpha, \mathbf{d}$ CPI17. a Aorta $p<0.05$ compared to all other groups, femoral artery $p<0.05$ compared to ileum. b, c No significant differences. d Aorta $p<0.05$ compared to all other groups. Panels (e) and (f) show Western blots for MYPT1 and ROCK1, respectively, from two separate gels. Equal amounts of protein from aorta (lanes 1,5), mesenteric artery (lanes 2, 6), intestine (lanes 3, 7), and urinary bladder (lanes 4,8) were separated. The third lane on each gel (white area) contained another sample not examined in this study

HSL and LPL (Fig. 5b, c), and of the FAS and ACC2 (Fig. 5d, e) were lower in the faster muscles with the higher SMHC-B expression.

\section{Discussion}

This study is an initial approach to develop a systematic view on the diversity of smooth muscle contractile system,
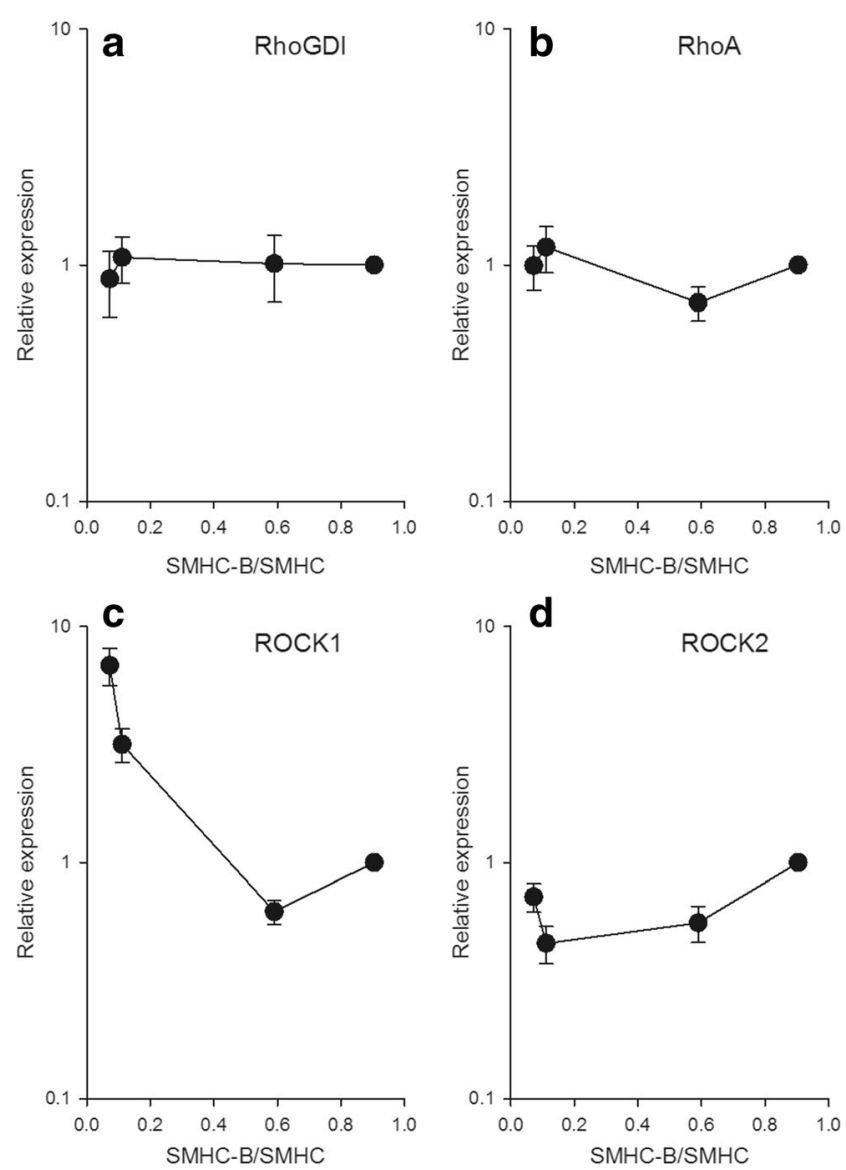

Fig. 2 Expression of signaling components in smooth muscles with different relative expression of SMHC-B. The Western blot data show from left to right: aorta, mesenteric artery, ileum, and urinary bladder, $n=$ 3-8. The data for the signaling components are given relative to the expression in the urinary bladder. a RhoGDI, b RhoA, c ROCK1, d ROCK2. a, b, d No significant differences. c Aorta $p<0.05$ compared to all other groups, mesenteric artery $p<0.05$ compared to ileum and urinary bladder

including a consideration of contractile, signaling, and metabolic properties. We base our analysis on four smooth muscle tissues with a large span in contractile properties, obtained from one species, the mouse. The main idea is to correlate the mechanical diversity to expression of signaling and metabolic pathways, and Table 3 summarizes the main properties of slow and fast smooth muscles.

We included a large elastic artery (aorta), muscular arteries (mesenteric artery and femoral artery), intestinal smooth muscle (longitudinal muscle of ileum), and the urinary bladder (detrusor muscle). The following values for the maximal shortening velocity ( $V_{\max }$, in muscle lengths per second, $\mathrm{ML} / \mathrm{s}$, at $20-22{ }^{\circ} \mathrm{C}$ ) in the different tissues can be obtained from the literature: (1) aorta $(0.015-0.07 \mathrm{ML} / \mathrm{s}$ in guinea pig and mouse [34, 43], (2) muscular artery (mouse caudal artery $\sim 0.08 \mathrm{ML} / \mathrm{s}$ at $37{ }^{\circ} \mathrm{C}$ [13], corresponding to about 0.02 at $22^{\circ} \mathrm{C}$ using $Q_{10}$ of 2.2 from [24]), (3) intestine (mouse ileum at $37{ }^{\circ} \mathrm{C} 0.29 \mathrm{ML} / \mathrm{s}$ [44], corresponding to $0.09 \mathrm{ML} / \mathrm{s}$ at $22{ }^{\circ} \mathrm{C}$; guinea pig ileum and taenia coli $0.11-0.20 \mathrm{ML} / \mathrm{s}[33,34,36]$ ), 

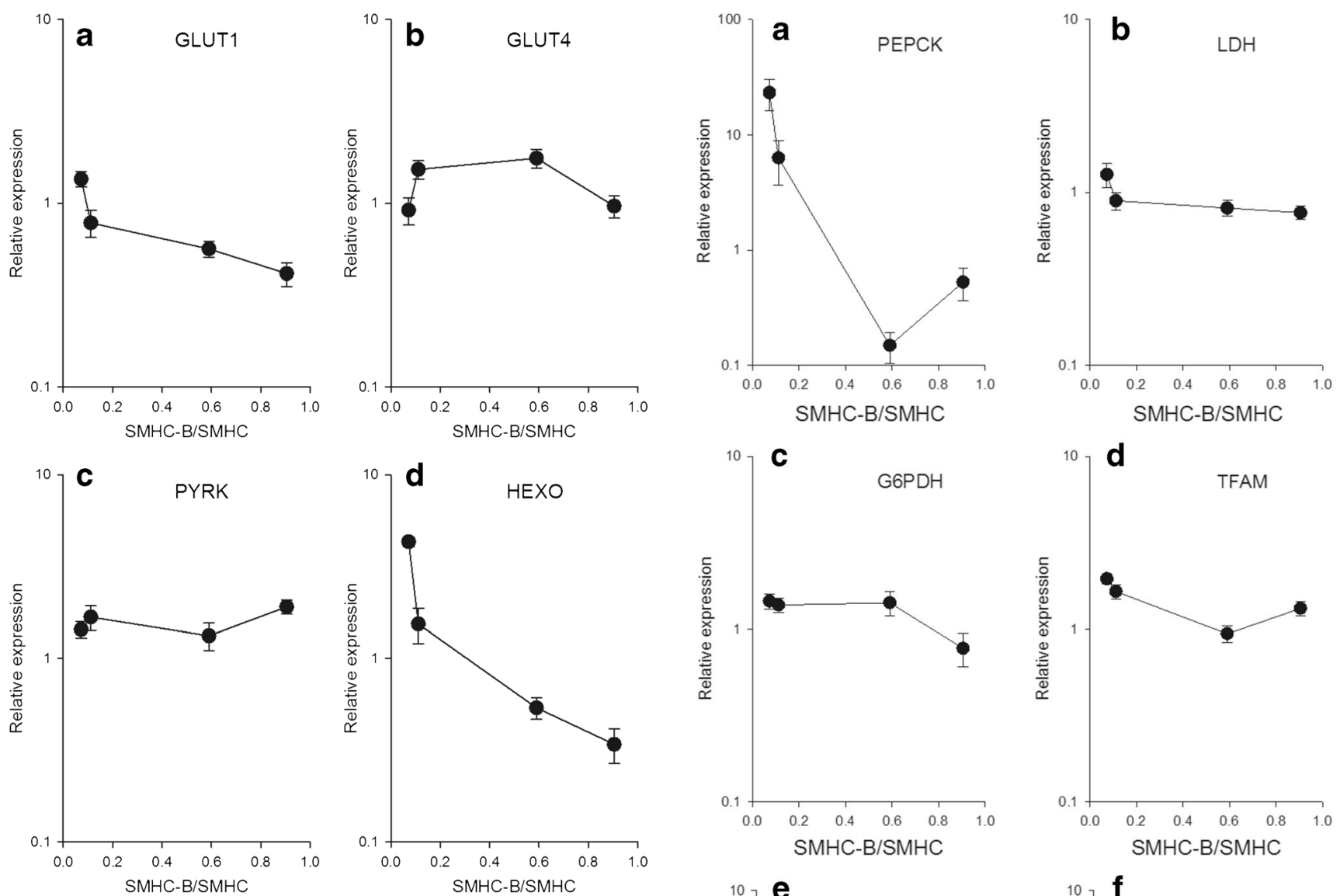

Fig. 3 Expression of metabolic components in smooth muscles with different relative expression of SMHC-B. The RT-qPCR data show from left to right: aorta, femoral artery, ileum, and urinary bladder, $n=$ 9-10. a GLUT1, b GLUT4, c PYRK, d HEXO. a Aorta $p<0.05$ compared to all other groups, femoral artery $p<0.05$ compared to urinary bladder. b Ileum $p<0.05$ compared to bladder and aorta, femoral artery $p<0.05$ compared to aorta. $\mathbf{c}$ No significant differences. d All groups are significantly $(p<0.05)$ different

and (4) urinary bladder (mouse $0.19 \mathrm{ML} / \mathrm{s}$ [47]). The examined muscles in the present study seem to be divided into slow arterial (aorta, muscular artery) and fast visceral (bladder) muscle types. The intestine possibly represents an intermediary group, although it in many of the measured parameters resemble the fast urinary bladder.

We thus included muscles with an about 5 -fold difference in $V_{\max }$ and showed, consistently with previous work, that the contractile kinetics (as evaluated from $V_{\max }$ ) correlates with expression of myosin heavy chain isoforms, cf. [3]. In general, $V_{\max }$ is also related to the rate of tension development, when different smooth muscles are compared $[22,36]$, suggesting that the kinetics of force generating cross-bridge transitions also vary between smooth muscle tissue types, although to a lower extent than $V_{\max }$ [36]. The tissues examined in the present study were obtained from mouse, but the difference in shortening velocity and myosin expression are also present in other experimental animals [3]. The slow arterial muscles could be denoted "tonic" and the fast visceral muscles
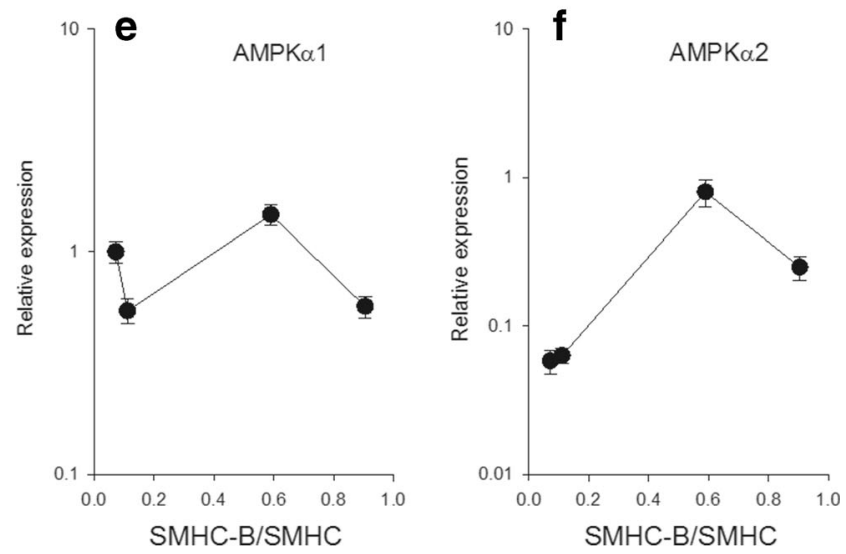

Fig. 4 Expression of metabolic components in smooth muscles with different relative expression of SMHC-B. The RT-qPCR data show from left to right: aorta, femoral artery, ileum, and urinary bladder, $n=$ 9-10. a PEPCK, b LDH, c G6PHD, d TFAM, e AMPK $\alpha 1$, f AMPK $\alpha 2$. a Aorta $p<0.05$ compared to all other groups, femoral artery $p<0.05$ from ileum and urinary bladder. b No significant differences. $\mathbf{c}$ Urinary bladder $p<0.05$ compared to all other groups. d Ileum $p<0.05$ compared to all other groups, aorta $p<0.05$ compared to urinary bladder. e Ileum $p<0.05$ compared to femoral artery and urinary bladder, aorta $p<0.05$ compared to femoral artery and urinary bladder. f Ileum $p<0.05$ compared to all other groups, urinary bladder $p<0.05$ compared to aorta and femoral artery

"phasic" consistently with the classification of Somlyo and Somlyo [49], but could not readily be classified into "single" and "multiunit" types according to the Bozler nomenclature [8]. These earlier classifications are based on the contractile 

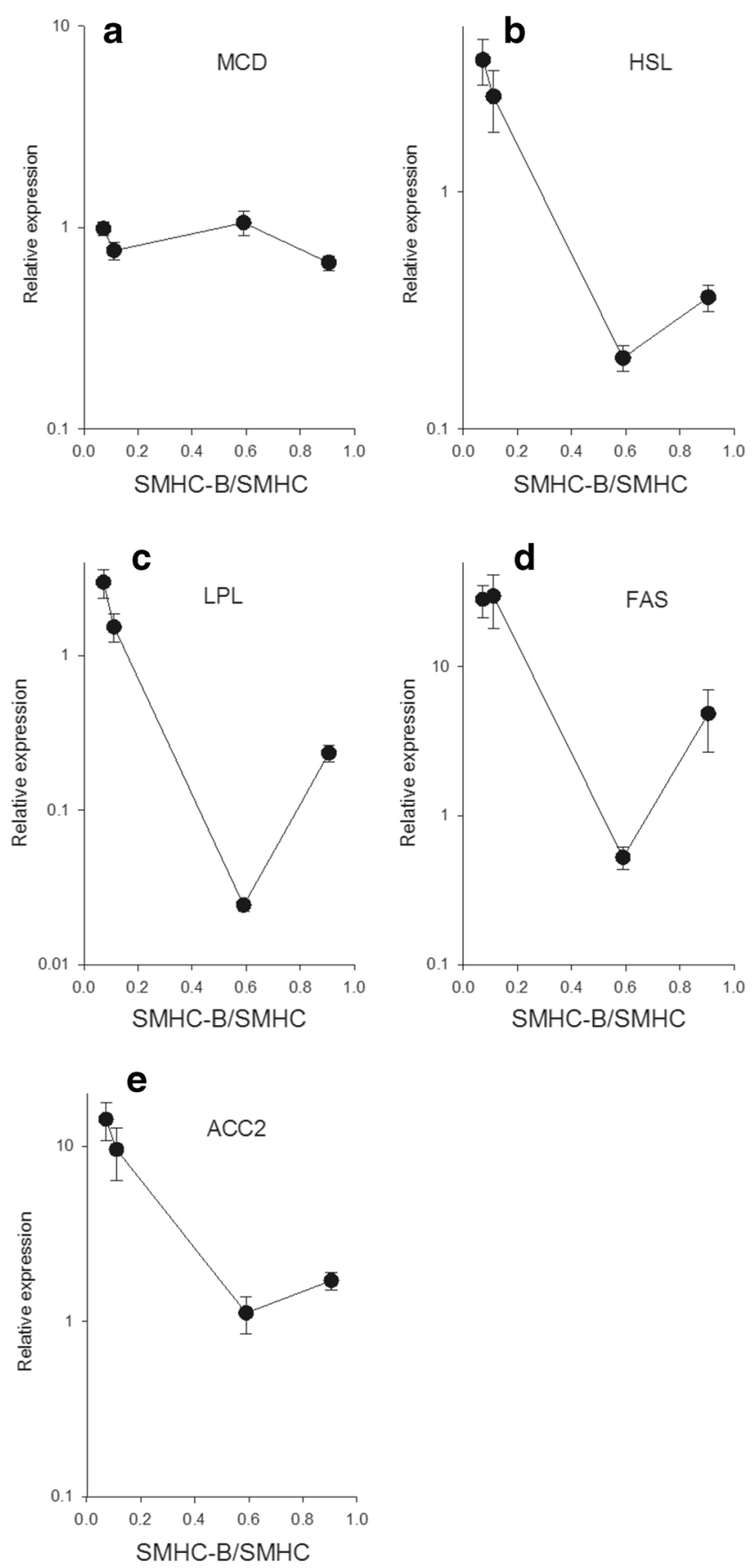

Fig. 5 Expression of metabolic components in smooth muscles with different relative expression of SMHC-B. The RT-qPCR data show from left to right: aorta, femoral artery, ileum, and urinary bladder, $n=$ 9-10. a MCD, b HSL, c LPL, d FAS, e ACC2. a Urinary bladder $p<0.05$ compared to aorta and ileum. b Aorta and femoral artery $p<0.05$ compared to ileum and urinary bladder. c All group significantly $(p<0.05)$ different. d Aorta and femoral artery $p<0.05$ compared to ileum and urinary bladder, ileum $p<0.05$ compared to urinary bladder. e Aorta and femoral artery $p<0.05$ compared to ileum and urinary bladder

responses of intact muscles after activation and on the properties of the nervous control. We, however, use a division into "fast" and "slow" based on the contractile kinetics and myosin heavy chain isoform expression. The urinary bladder and the aorta would represent these extremes. We cannot on the basis of the current data set exclude a continuous distribution or the presence of well-defined intermediate groups.

The maximal shortening velocity $\left(V_{\max }\right)$ in different muscles is generally correlated with the actin-activated myosin ATPase [6] and with the tension cost (i.e., the ATP turnover related to active force [11]). In this context, the generally slow and economical smooth muscle provides a physiological advantage over striated muscles during tension maintenance, e.g., in sustaining vascular tone [41]. Also, within the smooth muscle group, slower smooth muscles have a lower tension cost than comparatively faster smooth muscle types, e.g., rat aorta versus portal vein [2]. Characterizing the substrate and product dependence of cross-bridge interaction would give information on the rate-limiting reactions, and previous studies have compared slow and fast smooth muscle faster types [34]. In the slow muscle, $V_{\max }$ was less affected by lowering of [MgATP] and force was less inhibited by inorganic phosphate. However, the $V_{\max }$ of slow muscle is highly sensitive to MgADP [34] which correlates with a higher MgADP affinity to the rigor complex in slow tonic smooth muscle [17]. A further stronger MgADP binding is observed in smooth muscle expressing non-muscle myosin [32]. An important factor for determining the slow shortening velocity and tension economy is thus a high MgADP affinity, slowing crossbridge detachment, reducing the shortening velocity, and increasing the duty cycle in slow smooth muscle. Although smooth muscles have an economic contraction, and would not "fatigue" and lose force during sustained contractions, in a similar manner as striated muscles, the high MgADP sensitivity, rather than $P_{i}$ effects, will introduce an alternative mode of metabolic control of contraction affecting the contractile kinetics $\left(V_{\max }\right)$. The pronounced effects of MgADP will introduce a strong dependence of contractile kinetics on energy metabolism.

The contractile kinetics of smooth muscle is tightly linked to the regulation of contraction. An important phenomenon is the "latch" state where dephosphorylation of cross-bridges introduces a slow cycling and tension maintenance [14]. Work from the Somlyo group [21] has demonstrated that tonic/slow smooth muscles have lower phosphatase activity compared to phasic/fast smooth muscles. Lower content of the targeting subunit of myosin light chain phosphatase (MYPT1) has been demonstrated in tonic versus phasic smooth muscle [54]. We show that the MYPT1 content is lower in the slow smooth muscle compared to the fast, but that the catalytic subunit (PPI $\beta$ ) does not vary. Studies of newborn and hypertrophying urinary bladder smooth muscle have shown a lower expression of MYPT1 correlating with increased $\mathrm{Ca}^{2+}$ sensitivity $[7,15]$. This suggests that the slow smooth muscle types exhibiting lower MYPT1 have a slower kinetics in the dephosphorylation reaction and a higher $\mathrm{Ca}^{2+}$ sensitivity 
Table 3 Comparison of key contractile, signaling, and metabolic parameters of fast and slow smooth muscle types

\begin{tabular}{|c|c|c|}
\hline Parameters & "FAST" & "SLOW" \\
\hline \multicolumn{3}{|l|}{ Contractile parameters } \\
\hline Representative tissues & Urinary bladder & Aorta \\
\hline Shortening kinetics & High $V_{\max }$ & $\sim 5$ times slower $[34,36]$ \\
\hline Tension development & High rate of tension development & $\sim 2$ times slower $[36]$ \\
\hline Myosin types & $\begin{array}{l}\text { High LC17a } \\
\text { High SMHC-B } \\
\text { Low non-muscle myosin }\end{array}$ & $\begin{array}{l}\sim 16 \text { times lower }[3,36] \\
\sim 12 \text { times lower } \\
\text { Higher non-muscle myosin }[3,32]\end{array}$ \\
\hline ADP dependence & Low MgADP affinity & $\sim 36$ times higher affinity [34] \\
\hline ATP dependence & High MgATP affinity & $\sim 4$ times lower affinity [34] \\
\hline Phosphate dependence & High $P_{i}$ inhibition of force & $\sim 2-4$ times lower $\mathrm{P}_{\mathrm{i}}$ inhibition of force [34] \\
\hline \multicolumn{3}{|l|}{ Cell signaling } \\
\hline Dephosphorylation of myosin & $\begin{array}{l}\text { High expression of targeting subunit, MYPT1 no } \\
\text { difference in light chain phosphatase, catalytic subunit PP1 } \beta\end{array}$ & $\begin{array}{l}\sim 6 \text { times lower } \\
\text { No difference }\end{array}$ \\
\hline Protein kinase $\mathrm{C}$ pathway & $\begin{array}{l}\text { Low CPI17 } \\
\mathrm{PKC} \alpha \text { no difference }\end{array}$ & $\begin{array}{l}\sim 3 \text { times higher } \\
\text { No difference }\end{array}$ \\
\hline Rho-Rhokinase pathway & $\begin{array}{l}\text { Low ROCK1 } \\
\text { No difference in ROCK2, RhoA, and RhoGDI }\end{array}$ & $\begin{array}{l}\sim 7 \text { times higher } \\
\text { No difference }\end{array}$ \\
\hline \multicolumn{3}{|l|}{ Metabolic parameters } \\
\hline Glucose uptake and glycolysis & $\begin{array}{l}\text { Lower insulin-independent GLUT1 } \\
\text { No difference in insulin-dependent GLUT4 } \\
\text { Low hexokinase } \\
\text { PYRK no difference }\end{array}$ & $\begin{array}{l}\sim 3 \text { times higher } \\
\text { No difference } \\
\sim 13 \text { times higher } \\
\text { No difference }\end{array}$ \\
\hline Lactate production & $\begin{array}{l}\text { LDH no difference } \\
\text { Low LDH-H }\end{array}$ & $\begin{array}{l}\text { No difference } \\
\sim 1.4 \text { times higher [37] }\end{array}$ \\
\hline NADPH synthesis & G6DPH no difference & No difference \\
\hline Gluconeogenesis & Low PEPCK & $\sim 43$ times higher \\
\hline Mitochondrial signaling & TFAM no difference & No difference \\
\hline Metabolic sensing & $\begin{array}{l}\text { AMPK } \alpha 1 \text { no difference } \\
\text { High AMPK } \alpha 2\end{array}$ & $\begin{array}{l}\text { No difference } \\
\sim 5 \text { times lower }\end{array}$ \\
\hline Lipid metabolism & $\begin{array}{l}\text { Low HSL } \\
\text { Low LPL }\end{array}$ & $\begin{array}{l}\sim 10 \text { times higher } \\
\sim 13 \text { times higher }\end{array}$ \\
\hline Lipid synthesis & $\begin{array}{l}\text { Low FAS } \\
\text { Low ACC2 } \\
\text { MCD no difference }\end{array}$ & $\begin{array}{l}\sim 6 \text { times higher } \\
\sim 8 \text { times higher } \\
\text { No difference }\end{array}$ \\
\hline
\end{tabular}

To give an indication of the magnitude in differences, relative changes are approximated. Data obtained in the present study (estimated from mRNA or protein expression) are presented, and when appropriate, literature references are given (including other smooth muscle tissues with fast and slow characteristics)

compared to the faster smooth muscles. The latch phenomenon, i.e., the attachment of dephosphorylated myosin crossbridges, is prominent in slow smooth muscles [14]. One would expect that a lower phosphatase activity would lead to a lower tendency for dephosphorylated attached (latch) cross-bridges. This suggests that factors other than the phosphatase activity per se will contribute to the increased probability for latch in slow muscle. It is possible that the slower turnover and increased time in attached cross-bridge states in slow smooth muscles will increase the probability for dephosphorylation and latch states, a process that would be further enhanced by metabolic generation of MgADP.

We examined the two main upstream modulators of the phosphatase in the regulation of smooth muscle, protein kinase $\mathrm{C}$ (PKC), and Rho-Rhokinase [50]. Although the $\mathrm{PKC} \alpha$ expression showed little variation between the examined tissues, its target, the CPI17, was markedly higher in the slow tonic aorta, which correlates with previous data and the significant responses to PKC activation in this tissue [54]. RhoA and its modulator RhoGDI did not vary, but a clear correlation between SMHC-B and Rho-kinase 1 (ROCK1) expression was observed; the slower arterial muscles had higher ROCK1. This, in combination with a lower MYPT1 expression, might correlate to a difference in receptor activated $\mathrm{Ca}^{2+}$-sensitizing pathways and could result in a higher inhibition by Rho-kinase inhibitors in slow arterial versus fast bladder smooth. 
In view of metabolic effects via MgADP on the crossbridge kinetics, we addressed the question whether the difference in cross-bridge kinetics between smooth muscles could be linked to differences in metabolic energy turnover. Previous studies on smooth muscle have characterized the energy turnover associated with contraction, cf. [41, 42], and our study was primarily focused on differences in expression of metabolic pathways between smooth muscle types.

The GLUT1 and 4 glucose transporters were both expressed in the examined smooth muscles. Insulin receptors have been shown in smooth muscle [29], but the function of the insulin-responsive glucose transporter GLUT4 is less clear and the insulin-dependent glucose uptake is small [4]. Other studies have, however, shown expression of GLUT4 in smooth muscle, insulin-dependent glucose uptake, and effects on contractile function by the GLUT4 [e.g., 29, 9, 5, 39]. We show that the GLUT4 did not exhibit a correlation with SMHC-B expression, suggesting that the insulin-dependent glucose uptake is not a major factor determining the metabolic diversity. However, the insulin-independent GLUT1 was higher in slower muscles. Previous studies have shown that GLUT1 is expressed in aorta smooth muscle and that higher expression correlates with increased glucose uptake [25]. Hexokinase, the first and rate-limiting step in glycolysis, was markedly higher expressed in slow arterial muscles. Although the slow smooth muscles have lower energy consumption, they might require a continuous supply of energy to support more sustained contractions. The high expression of insulin-independent GLUT1 and of hexokinase would also make the slow arterial muscles more affected by high extracellular glucose levels, a potential factor of importance for development of atherosclerotic changes in large arteries in diabetic hyperglycemia.

Although the oxygen consumption in slow (aorta) smooth muscle is lower than in fast (portal vein) smooth muscle, the relative lactate production is higher in the slow muscle [2], reflecting an increased lactate production under aerobic conditions [41, 42]. The high expression of factors involved in glucose uptake in slow smooth muscle might be involved in providing glucose for ATP via glycolytic pathways producing lactate. The relatively higher lactate production is, however, not linked to altered expression of the lactate-producing $\mathrm{M}$ isoform of lactate dehydrogenase. Indeed, the slow aorta instead expresses more of the $\mathrm{H}$-form, less prone to produce lactate [37], suggesting that the conversion of pyruvate to lactate is not rate limiting for the lactate production in the slow muscle. No clear relationship could be demonstrated between pyruvate kinase (PYRK) and SMHC-B expression for all examined tissues. Since PYRK is the final step in glycolysis, an altered activity would not be a factor directing the glucose metabolism toward lactate in the slower smooth muscle. The aerobic glycolysis with lactate production is a prominent feature in smooth muscle [41, 42], similar to the Warburg effect of tumor tissues. The latter phenomenon has been linked to upregulation of hexokinase II [45], and the high expression of hexokinase can be an important contributor to the higher lactate production in slow smooth muscle. The glycolytic pathway has been proposed to support the activity of the membrane $\mathrm{Na} / \mathrm{K}$ ATPase [35]. Interestingly, the lactate production decreases in the aorta when extracellular $\left[\mathrm{Ca}^{2+}\right]$ and force are increased in depolarized muscle, whereas it increases in the portal vein [2], suggesting differences in regulation and recruitment of the aerobic glycolysis between different smooth muscle types. Although the slower muscles have higher expression of enzymes in glucose uptake and glycolysis, they also have markedly higher expression of PEPCK involved in gluconeogenesis, and the exact function of the varied PEPCK expression remains to be investigated.

Glucose-6-phosphate dehydrogenase (G6PDH) is a key enzyme in the pentose phosphate pathway, important for generating substrates for synthesis of nucleotides and producing NADPH which is involved in, e.g., fatty acid synthesis and protection against oxidative stress. G6PDH was slightly lower in the fast urinary bladder smooth muscle. The functional correlate to this finding is not yet clear. However, it has been shown that G6PDH is upregulated in isolated smooth muscle cells during mechanical/oxidative stress and that downregulation of the enzyme leads to increased oxidative stress [30]. In intact smooth muscle tissues, the activity of G6PDH is negatively correlated with the expression of contractile proteins [10], and a generally lower expression of G6PDH in the bladder might be important for maintaining a contractile phenotype. At the same time, oxidative stress of bladder smooth muscle has been proposed to be a pathological mechanism in bladder disorders [31], and a lower expression of G6PDH might be involved in these processes.

Adenosine monophosphate-activated kinase (AMPK) is a key metabolic sensor, activated by energy depletion and high AMP levels [19]. It affects several cellular functions including glucose uptake in skeletal muscle and inhibits agonist-induced contractions of arterial smooth muscle via effects on protein kinase $\mathrm{C}$ signaling [12]. Our profiling of AMPK $\alpha 1$ expression did not reveal any major differences between the examined tissues, although the AMPK $\alpha 2$ was slightly higher in the fast muscles, possibly reflecting higher demands on the metabolic control. TFAM, a key regulator of mitochondrial DNA [26], showed a small variation between the smooth muscle tissues with slightly higher values in the slow types, which could be a marker for a shift toward an oxidative metabolism possibly linked to a higher oxidation of fatty acids.

Both LPL and HSL enzymes responsible for uptake and breakdown of triglycerides were higher in the slower tonic muscles compare to the faster. This would suggest that the slower muscles are more adapted to metabolism of lipids. Although the MCD, important for fatty acid synthesis, was similar between tissues, both ACC 2 and FAS, two enzymes 
involved in fatty acid synthesis, were highly expressed in slower muscles. This even further points the fatty acids as an important substrate for the metabolism in slower muscles.

In summary, the main purpose of this study was neither to examine the exact role of all metabolic and signaling proteins nor to examine all steps in the different pathways. Rather, we aimed at obtaining a "finger print" of cellular components as a basis for characterizing the "fast" and "slow" smooth muscle types. Further work based on key parameters identified in the present study (as outlined in Table 3), including a broader range of smooth muscle tissues, would enable a further insight into the variability of smooth muscle and possibly identification of intermediate types or improved pathological markers. In a physiological situation, a slow smooth muscle is found in large and muscular arteries, where it will stay contracted for longer times at low energy expenditure. This is achieved by expression of specific myosin isoforms, accompanied by slower rates of deactivation and lower phosphatase expression. The Rho-kinase $1 \mathrm{Ca}^{2+}$-sensitizing component is highly expressed and in addition the sensitivity to PKC activation is enhanced. Although the energy turnover is low, the sustained contractions, while maintaining blood pressure, can be affected by varied levels of ADP resulting in "latch like" situations, which provides a link between contraction and a continuous input of metabolic energy from glucose and lipids.

Acknowledgements The study was supported by grants from the Swedish Research council (for A.A.-C1359), Karolinska Institutet, and EC FP7, INComb \#223234. We are grateful for the able technical help from Mrs. Qin Xu.

Open Access This article is distributed under the terms of the Creative Commons Attribution 4.0 International License (http:// creativecommons.org/licenses/by/4.0/), which permits unrestricted use, distribution, and reproduction in any medium, provided you give appropriate credit to the original author(s) and the source, provide a link to the Creative Commons license, and indicate if changes were made.

\section{References}

1. Ajtai K, Mayanglambam A, Wang Y, Burghardt TP (2013) Human tonic and phasic smooth muscle myosin isoforms are unresponsive to the loop 1 insert. ISRN Struct Biol 2013:634341

2. Arner A, Hellstrand P (1981) Energy turnover and mechanical properties of resting and contracting aortas and portal veins from normotensive and spontaneously hypertensive rats. Circ Res 48(4): 539-548. https://doi.org/10.1161/01.RES.48.4.539

3. Arner A, Löfgren M, Morano I (2003) Smooth, slow and smart muscle motors. J Muscle Res Cell Motil 24(2/3):165-173. https:// doi.org/10.1023/A:1026001513928

4. Arnqvist HJ, Dahlkvist HH (1987) Effect of in vivo exposure to insulin on glucose metabolism in rat aorta. Acta Physiol Scand 131(1): 109-112. https://doi.org/10.1111/j.1748-1716.1987.tb08211.x

5. Atkins KB, Prezkop A, Park JL, Saha J, Duquaine D, Charron MJ, Olson AL, Brosius FC $3^{\text {rd }}$ (2007) Preserved expression of GLUT4 prevents enhanced agonist-induced vascular reactivity and MYPT1 phosphorylation in hypertensive mouse aorta. Am J Physiol Heart Circ Physiol 293:H402-H408. https://doi.org/10.1152/ajpheart. 00854.2006

6. Bárány M (1967) ATPase activity of myosin correlated with speed of muscle shortening. J Gen Physiol 50(6):197-218. https://doi.org/ 10.1085/jgp.50.6.197

7. Boberg L, Poljakovic M, Rahman A, Eccles R, Arner A (2012) Role of rho-kinase and protein kinase $\mathrm{C}$ during contraction of hypertrophic detrusor in mice with partial urinary bladder outlet obstruction. BJU Int 109(1):132-140. https://doi.org/10.1111/j.1464410X.2011.10435.X

8. Bozler E (1948) Conduction, automaticity and tonus of visceral muscles. Experientia (Basel) 4(6):213-218. https://doi.org/10. 1007/BF02155366

9. Capron L, Housset E, Hartmann L (1980) Effects of in vitro and in vivo exposure to insulin upon glucose carbon accumulation in rat aorta: different patterns of response for intima-media and adventitia. Metabolism 29(9):859-865. https://doi.org/10.1016/00260495(80)90125-0

10. Chettimada S, Joshi SR, Dhagia V, Aiezza A, Lincoln TM, Gupte R, Miano JM, Gupte SA (2016) Vascular smooth muscle cell contractile protein expression is increased through protein kinase Gdependent and -independent pathways by glucose-6-phosphate dehydrogenase inhibition and deficiency. Am J Physiol Heart Circ Physiol 311(4):H904-H912. https://doi.org/10.1152/ajpheart. 00335.2016

11. Crow MT, Kushmerick MJ (1982) Chemical energetics of slowand fast-twitch muscles of the mouse. J Gen Physiol 79(1):147166. https://doi.org/10.1085/jgp.79.1.147

12. Davis B, Rahman A, Arner A (2012) AMP-activated kinase relaxes agonist induced contractions in the mouse aorta via effects on PKC signaling and inhibits NO-induced relaxation. Eur J Pharmacol 695(1-3):88-95. https://doi.org/10.1016/j.ejphar.2012.07.025

13. Davis MJ, Davidson J (2002) Force-velocity relationship of myogenically active arterioles. Am J Physiol Heart Circ Physiol 282(1):H165-H174. https://doi.org/10.1152/ajpheart.2002.282.1. H165

14. Dillon PF, Aksoy MO, Driska SP, Murphy RA (1981) Myosin phosphorylation and the cross-bridge cycle in arterial smooth muscle. Science 211(4481):495-497. https://doi.org/10.1126/science. 6893872

15. Ekman M, Fagher K, Wede M, Stakeberg K, Arner A (2005) Decreased phosphatase activity, increased $\mathrm{Ca}^{2+}$ sensitivity, and myosin light chain phosphorylation in urinary bladder smooth muscle of newborn mice. J Gen Physiol 125(2):187-196. https://doi.org/ 10.1085/jgp.200409212

16. Fisher SA (2010) Vascular smooth muscle phenotypic diversity and function. Physiol Genomics 42A(3):169-187. https://doi.org/10. 1152/physiolgenomics.00111.2010

17. Fuglsang A, Khromov A, Török K, Somlyo AV, Somlyo AP (1993) Flash photolysis studies of relaxation and cross-bridge detachment: higher sensitivity of tonic than phasic smooth muscle to MgADP. J Muscle Res Cell Motil 14(6):666-677. https://doi.org/10.1007/ BF00141563

18. Gong MC, Cohen P, Kitazawa T, Ikebe M, Masuo M, Somlyo AP, Somlyo AV (1992) Myosin light chain phosphatase activities and the effects of phosphatase inhibitors in tonic and phasic smooth muscle. J Biol Chem 267(21):14662-14668

19. Hardie DG (2011) AMP-activated protein kinase: an energy sensor that regulates all aspects of cell function. Genes Dev 25(18):18951908. https://doi.org/10.1101/gad.17420111

20. Himpens B, Matthijs G, Somlyo AV, Butler TM, Somlyo AP (1988) Cytoplasmic free calcium, myosin light chain phosphorylation, and force in phasic and tonic smooth muscle. J Gen Physiol 92(6):713729. https://doi.org/10.1085/jgp.92.6.713 
21. Himpens B1, Matthijs G, Somlyo AP (1989) Desensitization to cytoplasmic $\mathrm{Ca}^{2+}$ and $\mathrm{Ca}^{2+}$ sensitivities of guinea-pig ileum and rabbit pulmonary artery smooth muscle. J Physiol 413:489-503. https://doi.org/10.1113/jphysiol.1989.sp017665

22. Horiuti K, Somlyo AV, Goldman YE, Somlyo AP (1989) Kinetics of contraction initiated by flash photolysis of caged adenosine triphosphate in tonic and phasic smooth muscles. J Gen Physiol 94(4): 769-781. https://doi.org/10.1085/jgp.94.4.769

23. Jaworowski A, Anderson KI, Arner A, Engström M, Gimona M, Strasser P, Small JV (1995) Calponin reduces shortening velocity in skinned taenia coli smooth muscle fibres. FEBS Lett 365(2-3):167171. https://doi.org/10.1016/0014-5793(95)00451-E

24. Jaworowski A, Arner A (1998) Temperature sensitivity of force and shortening velocity in maximally activated skinned smooth muscle. J Muscle Res Cell Motil 19(3):247-255. https://doi.org/10.1023/A: 1005377016177

25. Kaiser N, Sasson S, Feener EP, Boukobza-Vardi N, Higashi S, Moller DE, Davidheiser S, Przybylski RJ, King GL (1993) Differential regulation of glucose transport and transporters by glucose in vascular endothelial and smooth muscle cells. Diabetes 42(1):80-89. https://doi.org/10.2337/diab.42.1.80

26. Kang D, Hamasaki N (2005) Mitochondrial transcription factor a in the maintenance of mitochondrial DNA: overview of its multiple roles. Ann N Y Acad Sci 1042(1):101-108. https://doi.org/10.1196/ annals. 1338.010

27. Kelley CA, Takahashi M, JH Y, Adelstein RS (1993) An insert of seven amino acids confers functional differences between smooth muscle myosins from the intestines and vasculature. J Biol Chem 268(17):12848-12854

28. Khromov AS1, Somlyo AV, Somlyo AP (1996) Nucleotide binding by actomyosin as a determinant of relaxation kinetics of rabbit phasic and tonic smooth muscle. J Physiol 492:669-673

29. King GL, Buzney SM, Kahn CR, Hetu N, Buchwald S, Macdonald SG, Rand LI (1983) Differential responsiveness to insulin of endothelial and support cells from micro- and macrovessels. J Clin Invest 71(4):974-979. https://doi.org/10.1172/JCI110852

30. Leopold JA, Loscalzo J (2000) Cyclic strain modulates resistance to oxidant stress by increasing G6PDH expression in smooth muscle cells. Am J Physiol Heart Circ Physiol 279(5):H2477-H2485. https://doi.org/10.1152/ajpheart.2000.279.5.H2477

31. Lin AT, Yang CH, Chen KK, Chang LS (2005) Detrusor mitochondrial lipid peroxidation and superoxide dismutase activity in partial bladder outlet obstruction of rabbits. Neurourol Urodyn 24(3):282287. https://doi.org/10.1002/nau.20109

32. Löfgren M, Ekblad E, Morano I, Arner A (2003) Nonmuscle myosin motor of smooth muscle. J Gen Physiol 121(4):301-310. https://doi.org/10.1085/jgp.200208720

33. Löfgren M, Fagher K, Wede OK, Arner A (2002) Decreased shortening velocity and altered myosin isoforms in guinea-pig hypertrophic intestinal smooth muscle. J Physiol 544(3):707-714. https:// doi.org/10.1113/jphysiol.2002.027060

34. Löfgren M, Malmqvist U, Arner A (2001) Substrate and product dependence of force and shortening in fast and slow smooth muscle. J Gen Physiol 117(5):407-418. https://doi.org/10.1085/jgp. 117.5.407

35. Lynch RM, Paul RJ (1983) Compartmentation of glycolytic and glycogenolytic metabolism in vascular smooth muscle. Science 222(4630):1344-1346. https://doi.org/10.1126/science.6658455

36. Malmqvist U, Arner A (1991) Correlation between isoform composition of the $17 \mathrm{kDa}$ myosin light chain and maximal shortening velocity in smooth muscle. Pflugers Arch 418(6):523-530. https:// doi.org/10.1007/BF00370566

37. Malmqvist U, Arner A, Uvelius B (1991) Lactate dehydrogenase activity and isoform distribution in normal and hypertrophic smooth muscle tissue from the rat. Pflugers Arch 419(3-4):230-234. https:// doi.org/10.1007/BF00371100
38. Morano I, Chai GX, Baltas LG, Lamounier-Zepter V, Lutsch G, Kott M, Haase H, Bader M (2000) Smooth-muscle contraction without smooth-muscle myosin. Nat Cell Biol 2(6):371-375. https://doi.org/10.1038/35014065

39. Park JL1, Loberg RD, Duquaine D, Zhang H, Deo BK, Ardanaz N, Coyle J, Atkins KB, Schin M, Charron MJ, Kumagai AK, Pagano PJ, Brosius FC $3^{\text {rd }}$ (2005) GLUT4 facilitative glucose transporter specifically and differentially contributes to agonist-induced vascular reactivity in mouse aorta. Arterioscler Thromb Vasc Biol 25:1596-1602

40. Patel CA, Rattan S (2006) Spontaneously tonic smooth muscle has characteristically higher levels of RhoA/ROK compared with the phasic smooth muscle. Am J Physiol Gastrointest Liver Physiol 291(5):G830-G837. https://doi.org/10.1152/ajpgi.00130.2006

41. Paul RJ (1980) Chemical energetics of vascular smooth muscle. Handbook of physiology: the cardiovascular system. Bethesda, MD: Am Physiol Soc 201-235

42. Paul RJ (1989) Smooth muscle energetics. Annu Rev Physiol 51(1): 331-349. https://doi.org/10.1146/annurev.ph.51.030189.001555

43. Rhee AY, Ogut O, Brozovich FV (2006) Nonmuscle myosin, force maintenance, and the tonic contractile phenotype in smooth muscle. Pflugers Arch 452(6):766-774. https://doi.org/10.1007/s00424006-0091-4

44. Risse PA, Kachmar L, Matusovsky OS, Novali M, Gil FR, Javeshghani S, Keary R, Haston CK, Michoud MC, Martin JG, Lauzon AM (2012) Ileal smooth muscle dysfunction and remodeling in cystic fibrosis. Am J Physiol Gastrointest Liver Physiol 303(1):G1-G8. https://doi.org/10.1152/ajpgi.00356.2011

45. Roberts DJ, Miyamoto S (2015) Hexokinase II integrates energy metabolism and cellular protection: Akting on mitochondria and TORCing to autophagy. Cell Death Differ 22(2):248-257. https:// doi.org/10.1038/cdd.2014.173

46. Schiaffino S1, Reggiani C (2011) Fiber types in mammalian skeletal muscles. Physiol Rev 91:1447-1531. https://doi.org/10.1152/ physrev.00031.2010

47. Scott RS, Li Z, Paulin D, Uvelius B, Small JV, Arner A (2008) Role of desmin in active force transmission and maintenance of structure during growth of urinary bladder. Am J Physiol Cell Physiol 295(2):C324-C331. https://doi.org/10.1152/ajpcell.90622.2007

48. Sjögren M, Alkemade A, Mittag J, Nordström K, Katz A, Rozell B, Westerblad H, Arner A, Vennström B (2007) Hypermetabolism in mice caused by the central action of an unliganded thyroid hormone receptor alpha1. EMBO J 26(21):4535-4545. https://doi.org/10. 1038/sj.emboj.7601882

49. Somlyo AP (1968) Somlyo AV (1968) Vascular smooth muscle. I. Normal structure, pathology, biochemistry, and biophysics. Pharmacol Rev 20(4):197-272

50. Somlyo AP, Somlyo AV (2003) $\mathrm{Ca}^{2+}$ sensitivity of smooth muscle and nonmuscle myosin II: modulated by $\mathrm{G}$ proteins, kinases, and myosin phosphatase. Physiol Rev 83(4):1325-1358. https://doi. org/10.1152/physrev.00023.2003

51. Somlyo AV, Matthew JD, Wu X, Khromov AS, Somlyo AP (1998) Regulation of the cross-bridge cycle: the effects of MgADP, LC17 isoforms and telokin. Acta Physiol Scand 164(4):381-388. https:// doi.org/10.1111/j.1365-201X.1998.tb10695.x

52. Somlyo AV, Vinall P, Somlyo AP (1969) Excitation-contraction coupling and electrical events in two types of vascular smooth muscle. Microvasc Res 1(4):354-373. https://doi.org/10.1016/ 0026-2862(69)90014-4

53. Walklate J, Ujfalusi Z, Geeves MA (2016) Myosin isoforms and the mechanochemical cross-bridge cycle. J Exp Biol 219(2):168-174. https://doi.org/10.1242/jeb.124594

54. Woodsome TP, Eto M, Everett A, Brautigan DL, Kitazawa T (2001) Expression of CPI-17 and myosin phosphatase correlates with $\mathrm{Ca}(2+)$ sensitivity of protein kinase $\mathrm{C}$-induced contraction in rabbit smooth muscle. J Physiol 535(2):553-564. https://doi.org/10.1111/ j.1469-7793.2001.t01-1-00553.x 